\title{
Analysis of the Causes and Countermeasures of Idle Warehousing
}

\section{Facilities in China}

\author{
Tu Min \\ jiangxi university of technology-engineer training center
}

Keywords: Logistics; Warehousing facilities; Idle; Countermeasure analysis

\begin{abstract}
Storage is an important part of logistics composition, and warehousing facilities are important in the field of storage, which makes the problems of warehousing facilities serious in the development of the logistics. In recent years, the idle warehousing facilities have become the factor affecting the development of logistics in China, so the way of analyzing the reasons of the idle storage facilities and proposing solutions are badly needed. The idle warehousing facilities increase the cost of storage, which leads to the increase of logistics cost, so effective solutions to the idle warehousing facilities will be in favor of the decrease of logistics cost and higher logistics profits.
\end{abstract}

\section{Overview}

Storage facilities are the connecting production and consumption, especially in the field of circulation; it is an important infrastructure, and is indispensable to orderly operation of social and economic activities.

At present, the current status of warehousing facilities is not going well in China. The current situation is: weak foundation, extensive management, decentralized structure, and low technique content. Especially in recent years, the problems are more and more obvious and serious.

With the continuous development of society, every company is devoted to reduce logistics costs in order to gain more economic profits. The decrease of logistics cost is necessary to remain invincible in the competition. The idle warehousing facilities undoubtedly increase the logistics cost, so it becomes essential to make reasonable planning and control of warehousing facilities, deepen the reform of warehouse management, and reduce the inventory cost.

\section{The status of domestic warehousing facilities}

Based on an overall analysis, the average scale of warehousing business is relatively small, and the economic benefit of warehousing industry is relatively low. From an overall perspective, the storage volume is large in China because of the shortage economy under the planned economy system, as large inventories can guarantee the continuity of production, which leads to the form of large warehouse. The current situation of warehousing industry is that the overall warehouse area is large, but the satisfactory warehouses are less. Firstly, the original warehouse is very old and backward, and cannot meet the requirements of modern inventory; secondly, a large number of warehouses in manufacturing industry couldn't be integrated and regrouped. Taking the Henan grain storage facilities as an example, the paper analyzes the problems of warehousing facilities in China. 
The existing problems are as follows: firstly, the warehousing facilities are old, the number of dangerous and old warehouse is big, and the potential of grain storage capacity is great; secondly, affected by the policy of holding up the market on purchase and storage, private enterprises built a large number of warehouses in recent years, but the building standards are very low; thirdly, the grain warehouse construction is hard to coordinate and supervise, which causes the unreasonable layout in some areas; fourthly, the overall grain logistics system construction falls behind in Henan province, which seriously affects the effective grain circulation, and leads to the grain overstock in some areas; fifthly, information construction of grain storage and logistics falls behind.

\section{The existing problems of warehousing facilities in China}

The causes of the warehousing facilities problems are that many enterprises are lack of adequate awareness of the warehouse automation and mechanization, which leads to the development of modern technology are falling behind. The modern warehouses at abroad mentioned above all have advance warehousing facilities, such as warehouse management software in US, monomer warehouse in Netherlands, etc. However, the current actual conditions in China are that most of the small and medium-sized enterprises are operated by manual work; the huge differences in storage facilities seriously affect the efficiency of warehouse operation. Although some of the small and medium-sized enterprises have some information-related applications, the awareness is still not strong and the gap is relatively large when compared with large enterprises. The cost of each logistics link is lower compared with developed countries, but the comprehensive cost of the whole logistics process is far higher than that of the developed countries. One of the important factors is that the information degree of each link in the enterprise is relatively lower, information sharing is insufficient, which leads to large storage capacity, loss of transportation capacity, and lots of idle warehousing facilities.

Many existing state-owned large warehouses were built in the last century, such as those granaries in Henan mentioned above, which can no longer be used and should be declared worthless, so these warehouses are left unused.

Although some large enterprises are using automated stereoscopic warehouses, the stereoscopic warehouse in China exist the weaknesses such as low utilization ratio, poor effect, uncertain scale, and inconspicuous advantages, which causes the waste of lots of storage area resources, especially those enterprises with low production capacity and single product, whose idle warehousing facilities problems are serious.

The base of warehousing facilities is big in China, but the layout is not reasonable enough. Each enterprise sets up the warehouse to meet their needs, which leads to the huge number of warehouse. Their warehouses are centralized in the economically developed regions, which leads to the polarized situation that the warehousing facilities are idle in some areas but not enough in other areas.

\section{Countermeasure analysis on the idle warehousing facilities in China}

According to the above analysis, there are lots of problems on idle resources in the warehousing facilities, which greatly restricts the development of logistics economy, so it is very necessary to solve these idle resources problems. Hereby, some suggestions are given as follows: 


\section{Revitalize assets}

Revitalize the assets by making full use of existing equipment. The important measures to improve economic benefits in the process of transforming management mechanism for logistics are to develop idle resources, revitalize existing asset and improve utilization rate of equipment. Put idle resources fully in the open market, break the industry and administrative areas boundaries, and allow the market for effective and reasonable configuration of resources. Introduce relevant policies to encourage professional institutions to manage idle equipment, extend equipment information communication channels, and strengthen information service means. Through normal channels, idle facilities realize paid transfers, sell, lease and swap. In order to improve the efficiency of warehouse management, it is necessary to constantly absorb and apply the latest achievements of social science and natural science, such as advance planning, network planning, decision-making theory, etc. Combining with the characteristics of warehousing, applying the $\mathrm{ABC}$ classification method and inventory control theory in the inventory control, the good warehouse management promotes the rationalization of commodity circulation and achieves the maximum of profit and efficiency. For example, the emergence of automatic replenishment program can better control the inventory to lower the business risks and reduce the enterprise cost.

\section{Allocate resources reasonably}

Realize resources sharing as far as possible, and prevent the unnecessary waste of resources. Research and popularize modern logistics management and operation mode; combine the production process and automation warehouse technology to increase the speed of internal logistics; develop e-commerce using network technology and realize network of logistics means and organization; make full use of the resources of external related industries and enterprises, and truly achieve the scale, resource-sharing and risk-sharing logistics operation; construct and use together with manufacturers, wholesalers and retailers the automated stereoscopic warehouse, and become the processing base for inventory, distribution, transportation, and transit, and backup force of their own logistics base; provide third-party logistics service and form complete logistics distribution system; complete the logistics tasks of any areas within shortest possible time and make the logistics cost reasonable; integrate horizontally as far as possible, and open their own logistics resources to improve the market share.

\section{Strengthen talent cultivation}

Comprehensively enhance staff quality, improve the management mechanism of automation warehouse and strengthen the cultivation of logistics talent; the efficient use of logistics facilities requires suitable logistics environment and scientific management, which needs high quality talents. Under the current conditions of being lack of practical experience, the approach "learning at abroad, applying at home" can be adopted, that is to study in the developed countries, invite professional or college teachers to introduce experience, pass on knowledge and organize a learning group or recruit professional technical personnel of logistics major in the technical college, solve the problem of bing lack of operators and maintenance personnel. Realize localization as soon as possible and suit the market demands. Colleges and universities should pay attention to the principle of combining theory with practice in the cultivation of professional talent. The primary-level workers of logistics should be trained regularly and occasionally, and the training and examination should be attached great importance. Strengthen the communication between schools and enterprises. According to the needs 
of the society, colleges and universities should update the teaching methods and contents. Meanwhile, strengthen the communication between colleges and enterprises, and provide students with more internship opportunities, which makes students apply what they are learning in the practice in a better way.

\section{Reasonable planning}

Before the planning of warehouse, determine the required form of storage room, partition and classify inventory materials according to certain standard. The basic principle of warehouse layout design is: use efficient material handling facilities and standard operation process; prepare efficient store design scheme; minimize the space occupied by passageway; make full use of warehouse stacking capacity. Divide the storage and picking areas reasonably within the limited storage space of private warehouses, and well design the layout of the two areas, which will undoubtedly improve the working performance and warehouse utilization ratio.

\section{Strengthen technical renovation}

Strengthen technical renovation, operation and management. The development of modern logistics requires modern warehouse management; information and advanced technology guided by information are effective way for modernization of warehousing industry. The traditional management mode of manual operation, in which the information is recorded manually, should be replaced by electronic means, digital and networked computer management and mechanized and automated operation management. The warehousing management technology is mainly renovated from the following two aspects: 1) based on the market demand, determine the construction and renovation of storage hardware facilities; carry out the reform of mechanization, automation and intelligence, and improve the utilization rate of storage resources and efficiency of warehouse management. 2) Build thorough powerful warehouse management system and carry out the technology renovation of warehouse information and network. In the aspect of software facilities, there are several levels of choices: (1) single warehousing and transportation management software; (2) local area network (LAN) of the company (3) information sharing with customers and partners through extranet and Internet.

\section{Notable links and equipment}

Pay attention to using logistics information technology and warehouse management system in each link of warehousing management, such as loading and unloading management, goods sorting, check, and inventory control, which can greatly improve warehouse management efficiency, reduce errors, and realize information sharing with partners through enterprise internal network and extranet. Nowadays, the radio frequency identification technology, bar code technology, scanning technology and data acquisition technology are increasingly used in handling facilities, such as forklift, stacking cars, automatic guided vehicle, conveyors, etc. Mobile robot as flexible logistics tool is also increasingly playing an important role in flexible production, storage and product delivery. 


\section{References}

[1] Wu Huijie, Li Jing. The current status, reason and countermeasure analysis on storage industry in China--based on the development of storage industry in developed countries [J]. Practice in foreign economic relations and trade, 2011, 08:81-84.

[2] Wang Limin. Design trend of modern logistics warehousing facilities [J].China logistics and purchasing, 2012, 01:46.

[3] Song Feng. The survey and reflection on the storage facilities construction of state-owned grain collection and storage enterprises under the new situation [J].Science and technology of grain and oil storage, 2012,01:35-37.

[4] Yang Haiying, Guo Zhitao. The current status and development of China grain storage facilities construction [J].Grain technology and economy, 2013, 03:31-33.

[5] Tan Xiao. Exploration on the application of IOT in the logistics storage management [J]. Technology innovation and application, 2014, 03:276.

[6] Xia Jianhui, Li Jie. Analysis on the design and realization of logistics warehousing management system [J].modern economic information, 2014, 01:90-91.

[7] Zhang Haiying. Study on the problems of logistics storage technology renovation [J].Modern enterprise education, 2013, 24:563.

[8]George Ioannou,Manolis N. Kritikos. Optimization of material handling in production and warehousing facilities[J]. Operational Research,2013,43:

[9]Anonymous. Sika Corp opens new warehousing facility[J]. Trailer / Body Builders,2011,526:.

[10]Anonymous. Groom Energy and Digital Lumens Deploy Digital Lumens Intelligent Lighting System in Interstate Warehousing facilities[J]. Wireless News,2011,: 